\title{
Mass transfer enhancement in a three-phase fluidized bed electrochemical reactor
}

\author{
Gajulapalli V.S.K. Reddy ${ }^{1 *}$, Kasala V. Ramesh ${ }^{2}$ \\ ${ }^{1}$ Department of Chemical Engineering, MVGRCE, Vizianagaram 535005, India \\ ${ }^{2}$ Department of Chemical Engineering, Andhra University, Visakhapatnam 530003, India
}

Corresponding Author Email: kvramesh69@yahoo.com

https://doi.org/10.18280/ijht.360124

Received: 22 October 2017

Accepted: 18 September 2017

\section{Keywords:}

mass transfer coefficient, fluidized bed, three-phase fluidization, augmentation, turbulent promoter.

\begin{abstract}
An assembly consisting of a string of hemispherical elements arranged concentrically on a rod essentially acted as a displaced augmentative device. This assembly was placed coaxially in a three-phase fluidized bed. Nitrogen gas, an electrolyte and glass spheres were used as gas, liquid and solid phases respectively. Limiting current technique was employed to obtain mass transfer coefficient data. Maximum augmentation realized in the present study was about 18 times in comparison with homogeneous pipe flow. Present investigation revealed that the fluctuations in mass transfer coefficients in axial direction were within $\pm 10 \%$. The mass transfer coefficient increased with superficial gas velocity and particle diameter. The mass transfer coefficient decreased with pitch and characteristic length. Superficial liquid velocity and promoter rod diameter have not shown any noticeable influence on mass transfer coefficient. The entire mass transfer coefficient data obtained in the present study were subjected to least squares regression analysis and a correlation equation has been obtained.
\end{abstract}

\section{INTRODUCTION}

Gas-liquid fluidized beds find many applications in chemical, petrochemical and bioprocessing industries. The successful operation of three phase fluidized beds depends on establishment of adequate contact among the constituent phases that leads to good temperature control and enhanced heat and mass transfer rates. The enhanced heat and mass transfer rates also facilitate the reduction of the size of operating equipment and hence decrease the burden of capital to be invested. [1-8]. Many techniques employed for achieving enhanced heat and mass transfer rates have been summarized and presented by Bergles et al. [1].

Table 1. Range of variables investigated in the present study

\begin{tabular}{cccc}
\hline S.No & Parameters studied & Minimum & Maximum \\
\hline 1 & Gas flow rate X $10^{-3}\left(\mathrm{~m}^{3} / \mathrm{s}\right)$ & 0.05 & 0.25 \\
2 & Liquid flow rate X $10^{-3}$ & 0.27 & 0.67 \\
& $\left(\mathrm{~m}^{3} / \mathrm{s}\right)$ & & \\
3 & Diameters of the rod $(\mathrm{cm})$ & 0.6 & 1.3 \\
4 & Pitch $(\mathrm{cm})$ & 3 & 10 \\
5 & Characteristic Length $(\mathrm{cm})$ & 3 & 5 \\
6 & Size of the particles $(\mathrm{mm})$ & 2.913 & 5.6 \\
\hline
\end{tabular}

With the aim of heating the contents of the bed, immersed heaters are sometimes arranged. Setting up coils in the bed serves the purpose of either heating or cooling. During fabrication of the equipment geometric irregularities are more likely to occur. All these things come in the way of flowing fluids effecting a change in flow paths that is more likely to favour the enhancement in heat and mass transfer rates; thus they obviously act as turbulent promoters. Accommodating turbulent promoters in the fluidized bed for the sake of obtaining enhanced heat and mass transfer rates is one of the augmentative techniques often employed. Although numerous studies were carried out in enhancing mass transfer rates in homogeneous flow and liquid fluidized beds [9-10], such studies in three phase fluidized beds were scarce. Literature survey revealed that very few studies [4-8] were taken up to investigate the systematic effects of the geometry of the internals on mass transfer in three phase fluidized beds. Promoter internals such as helicoidal tape wound on a rod, twisted tapes, strings of discs, angled discs and spheres were employed in these studies. Among these internals disc promoter yielded high mass transfer rates, but the mass transfer coefficient was not uniform in axial direction wherein fluctuations realized were \pm 70 percent about mean. Helicoidal tapes and twisted tapes yielded nearly uniform mass transfer coefficients in the longitudinal direction, but fabrication was very difficult. Although fabrication of disc promoter seems to be simple and easy, wear and tear effects are more hence frequent replacement is necessary. In view of these disadvantages, it is felt that there is a need for a new promoter that yields higher and nearly uniform mass transfer coefficients with ease of fabrication. It is found that in homogeneous flow the coaxially placed string of hemispheres yielded enhanced mass transfer coefficients with fluctuations being nearly marginal [9]. Fabrication of this element is also very easy. Also, to the best of the knowledge of the authors, so far no work on wall-to-bed mass transfer is carried out using string of hemispheres as internal in three phase fluidized bed electrochemical reactors [10]. Therefore in the present investigation the effects of liquid and gas superficial velocities, particle size, pitch and characteristic length on the wall-to-bed mass transfer rates in gas-liquid-solid fluidized bed have been studied. Limiting current technique is used to obtain mass transfer coefficient data. An electrolyte belonging to ferricyanide - ferrocyanide redox couple was employed as 
liquid phase. Nitrogen was used as gas phase. Glass balls of different diameters were used as bed material. The range of variables covered in the present study are compiled in Table 1.

\section{EXPERIMENTAL PROCEDURE}

The experimental set up shown in Figure 1a mainly consisted of a vertical column with three segments namely a calming section (C), a test section (T) and a gas-liquid separator $(\mathrm{S})$. The calming section was made of a copper pipe of $6.73 \mathrm{~cm}$ inner diameter and $107 \mathrm{~cm}$ long. It was equipped with a sparger and an inlet at the bottom of the section to let in both gas and liquid into the column. Different sizes of pebbles were placed in the calming section to nullify tangential entry effects, to ensure uniform mixing of gas and electrolyte and to minimize flow fluctuations. A grid made of stainless steel was provided between calming section and test section for even distribution of gas and liquid electrolyte into the bed as well as to retain the solid particles and to hold the promoter internal. The calming section was coupled to the main test section (T) by means of a flange $\left(\mathrm{F}_{1}\right)$.

The test section (T) was made of transparent Perspex tube of $6.73 \mathrm{~cm}$ inner diameter and $60 \mathrm{~cm}$ long. This section was provided with 34 copper point electrodes, each of diameter $3.42 \mathrm{~mm}$ arranged with a spacing of $1 \mathrm{~cm}$ in line on the surface of the test section. One end of these electrodes was fixed even with inner surface of the test section while the other end projected outward served as terminal for connecting the electrodes to the external circuit. Two pressure taps $\mathrm{P}_{1}$ and $\mathrm{P}_{2}$ were provided at the top and bottom of the test section. These are connected to the limbs of the U-tube manometer (M) to measure pressure drop across the test section. Hemispherical elements were arranged as a string on a central rod as shown in Figure 1b. This assembly was used as promoter internal.

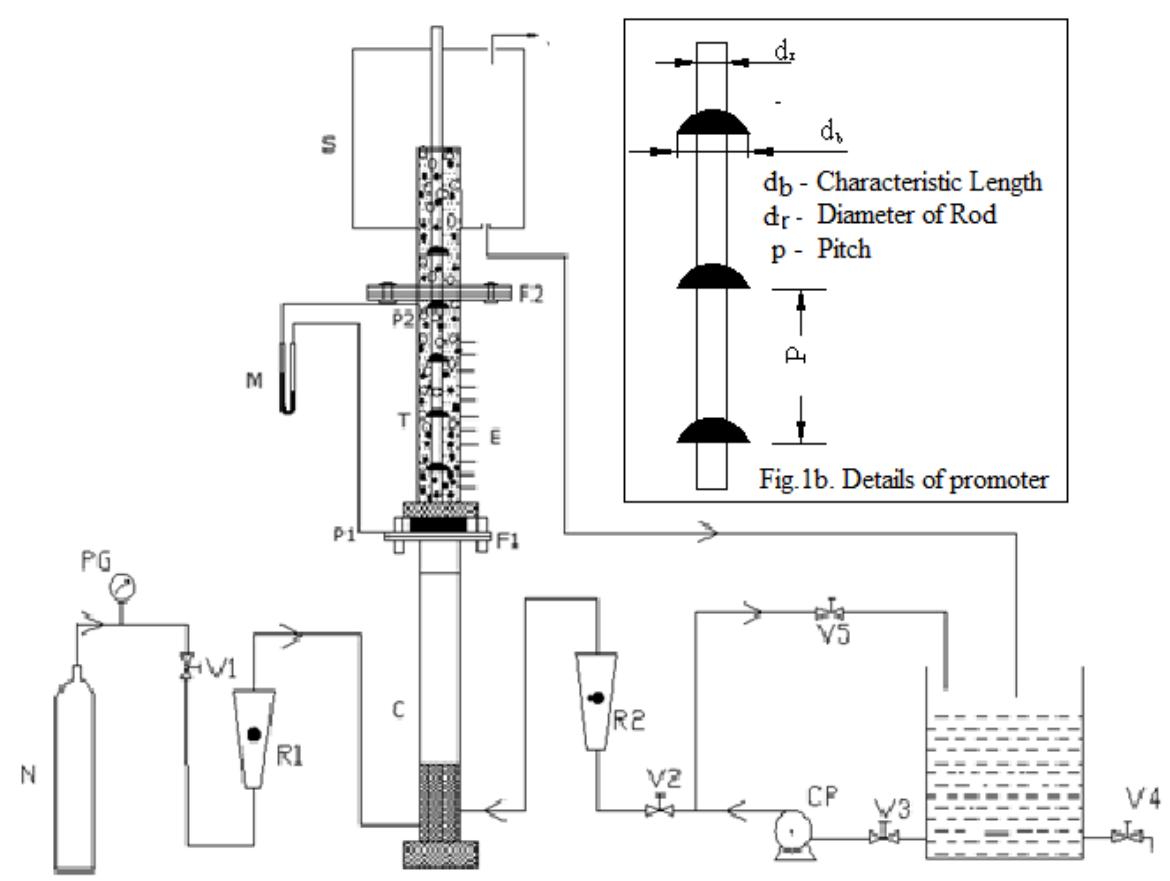

Figure 1a. Line diagram of experimental unit Figure 1b. Details of promoter

C-Calming section; T- Test section; S - Gas-liquid separator; E - Electrodes; F1and F2 - Flanges; N -Nitrogen gas cylinder; CP - Centrifugal pump; R1-Gas rotameter; R2-Liquid rotameter; ST - Storage tank; P1 and P2 - Pressure tapings; M - Manometer; V - Exit; V1 to V5 - Valves

The storage tank with 100 liters capacity, containing electrolyte, was completely covered with a lid to avoid continuous contact of electrolyte with the surrounding air. The bottom side of the storage tank was connected to the inlet of the calming section via centrifugal pump (CP) and flow measuring device. The by-pass line was provided at the discharge end of the pump with a globe valve to control the flow through rotameter. A nitrogen cylinder was connected to the sparger provided at the bottom of the calming section through a rotameter to admit the metered nitrogen gas into the experimental column. The gas-liquid separator (S) was also made of transparent Perspex tube, was coupled to the test section $(\mathrm{T})$ by means of a flange $\left(\mathrm{F}_{2}\right)$. The liquid electrolyte through the column was recirculated from the bottom of the gas separator to the storage tank (ST). The gas escapes through the vent $(\mathrm{V})$ provided in the gas-liquid separator.
Before startup of the experimental work, the surfaces of the point electrodes placed in the test section were polished with a fine emery paper and cleaned thoroughly to remove any depositions. About 80 liters of electrolyte consisting of equimolar solution of potassium ferrocyanide and potassium ferricyanide of $0.01 \mathrm{~N}$ with $0.5 \mathrm{~N}$ of sodium hydroxide was prepared using distilled water. The rotameter was calibrated using this electrolyte. The electrolyte from the storage tank and gas flow from the nitrogen cylinder were metered and circulated through the test conduit. The flow rates were regulated and measured using control valves and rotameters placed in the flow lines. The pressure difference across the test section was measured using a U-tube differential manometer.

The limiting current $i_{L}$ was measured using similar methodology as reported by Lin et al. [11] and Harvind Kumar et al. [12]. The electrode reaction involved in this study was: 
$\left[\mathrm{Fe}(\mathrm{CN})_{6}\right]^{3-}+\mathrm{e} \rightarrow\left[\mathrm{Fe}(\mathrm{CN})_{6}\right]^{4}$

The mass transfer coefficient $\mathrm{k}_{\mathrm{L}}$ was calculated using measured limiting current value from the equation:

$\mathrm{k}_{\mathrm{L}}=\frac{\mathrm{i}_{\mathrm{L}}}{\mathrm{nAFC}_{\mathrm{o}}}$

\section{RESULTS AND DISCUSSION}

In a liquid fluidized bed Jagannadha Raju and VenkataRao [13] observed nearly tenfold improvement in mass transfer coefficient values when compared to homogeneous flow. The reasons for improvements in mass transfer coefficients in fluidized bed can be as follows. It is reported that the main resistance to the mass transfer is offered by the resistance film that appears on the transfer surface [11-13]. When liquid electrolyte flows through a bed of solid particles, due to reduced available flow area, the resulting local liquid velocities would be very high. This increased momentum of the liquid electrolyte shears away the resistance film on the electrode surface, hence the film becomes thin yielding increased mass transfer coefficients. Also the fluidized particles move and circulate freely in the bed, strike electrode surface causing further reduction of the resistance film resulting in an increase in the mass transfer coefficients. By adding gas phase to the liquid fluidized bed, bubble flow appears in the bed. These bubbles accelerate upwards owing to large buoyancy forces leading to vigorous churning action. This scouring action significantly contributes to the reduction of resistance film thickness hence an increase in mass transfer coefficient can be realized. Introduction of the turbulent promoter into the three-phase fluidized bed is likely to further enhance mass transfer coefficient because of reduced flow area and changed flow patterns of the fluids $[4,14]$.

\subsection{Augmentation}

Figure 2 shows the mass transfer coefficient data obtained in the present study for different flow systems in the presence of the promoter element. Plots A, B, C and D represent mass transfer coefficient data obtained in homogeneous flow, homogeneous flow with turbulent promoter, liquid fluidized bed with turbulent promoter and gas-liquid fluidized bed with turbulent promoter respectively.

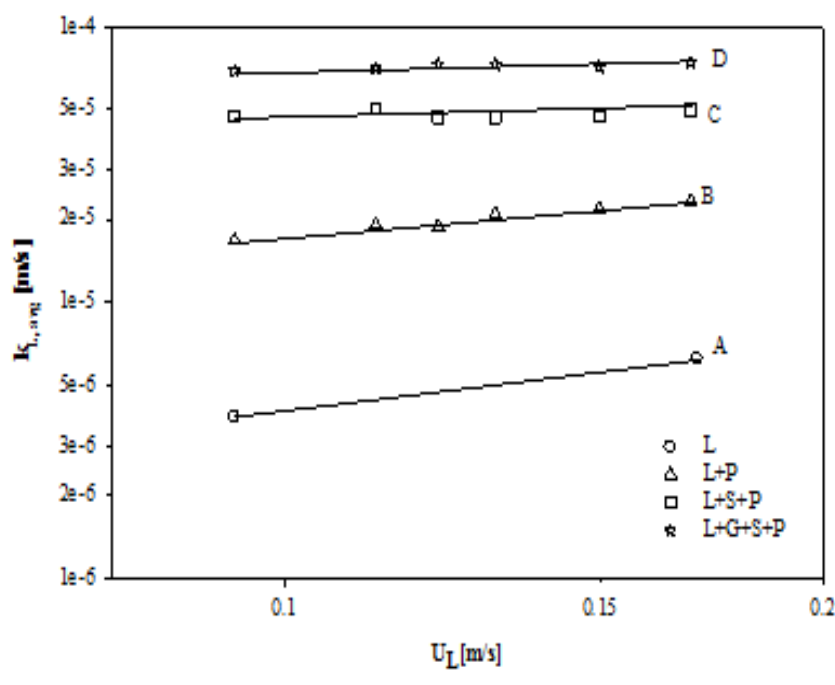

Figure 2. Augmentation of mass transfer coefficient

It is observed that addition of each phase turns out to yield significant improvement in mass transfer coefficients. The data for plot A were predicted from Lin et al [11] which represent the homogeneous flow of electrolyte. Plot B shows the present experimental data obtained for the case of homogeneous flow in the presence of coaxially placed string of hemispheres. These data are found to be consistent with that of Reddy et al. [9]. Plot $C$ represents the present experimental data in liquid fluidized bed with promoter. The mass transfer coefficient data in three-phase fluidized bed with promoter is shown in plot D. A comparison between plots A and B reveals that the introduction of promoter into homogeneous flow yielded an enhancement in mass transfer coefficient up to 4.5 times. Addition of fluidized solids to this system resulted in realizing further improvement of $180 \%$ in mass transfer coefficient (plots B and C). Finally addition of gas to this system yielded an additional 50\% enhancement in mass transfer coefficient (plots $C$ and D). Overall enhancement in mass transfer coefficient in three phase fluidized bed with the present promoter internal is 18 times over homogeneous flow in empty conduit (plots D and A) at a liquid velocity of 0.0937 $\mathrm{m} / \mathrm{s}$. Therefore it can be inferred that highest mass transfer coefficient values can be realized in three phase fluidized beds in the presence of string of hemispheres.

\subsection{Longitudinal variation of mass transfer coefficient}

In previous studies where experiments were carried out to investigate liquid - wall mass transfer in the presence of disc promoter in homogeneous flow [15], gas-liquid up flow bubble columns [16] and three phase fluidized beds [5], it was found that the mass transfer coefficients deviated up to a maximum \pm 70 about mean value in the axial direction. In the present study mass transfer coefficient data were obtained in the presence of string of hemispheres as internal $\left\{\mathrm{d}_{\mathrm{r}}=0.6 \mathrm{~cm}\right.$; $\left.\mathrm{p}=5.0 \mathrm{~cm} ; \mathrm{d}_{\mathrm{b}}=4 \mathrm{~cm}\right\}$ in three phase fluidized beds at constant gas and liquid velocities, to inspect whether such fluctuations exist or not. Mass transfer coefficients calculated from the obtained limiting current data were plotted against axial length and shown in Figure 3. A close inspection of the plots of Figure 3 indicates that the fluctuation in mass transfer coefficients about the mean value were not more than $\pm 10 \%$. 
The mechanism can be conceived to be as follows.

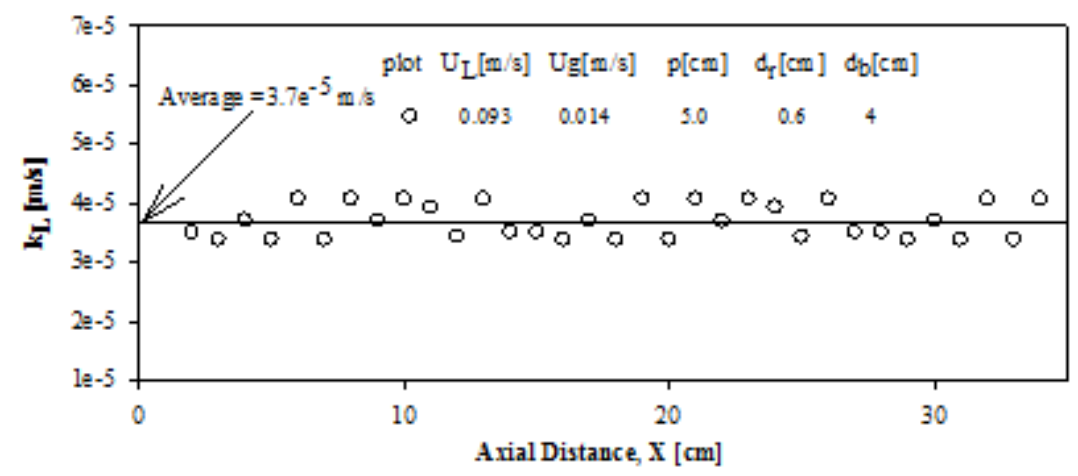

Figure 3. Axial variation of mass transfer coefficient in the test section

In Figure $4 \mathrm{a}$, the region bounded between aa and $\mathrm{a}^{1} \mathrm{a}^{1}$ can be considered to be free flow zone where there are no obstructions. Between two adjacent hemispheres wake zone appears around the central rod of the promoter. A close inspection of Figure 4a reveals that these wake zones have their center of mass towards column wall and therefore shifts into main stream fluid. Also trapped solid particles in the wake zone come back into main stream. The portion of wake zone that entered into the free stream zone would be sheared off due to momentum of the liquid.

To fill the void space appeared due to shifting of the wake zone towards wall, liquid is more likely to flow from free stream zone towards the central rod as is depicted in Figure $4 \mathrm{~b}$. Therefore these wakes get deformed and move towards the column wall. This leads to the flow of liquid from the free stream into the void space.
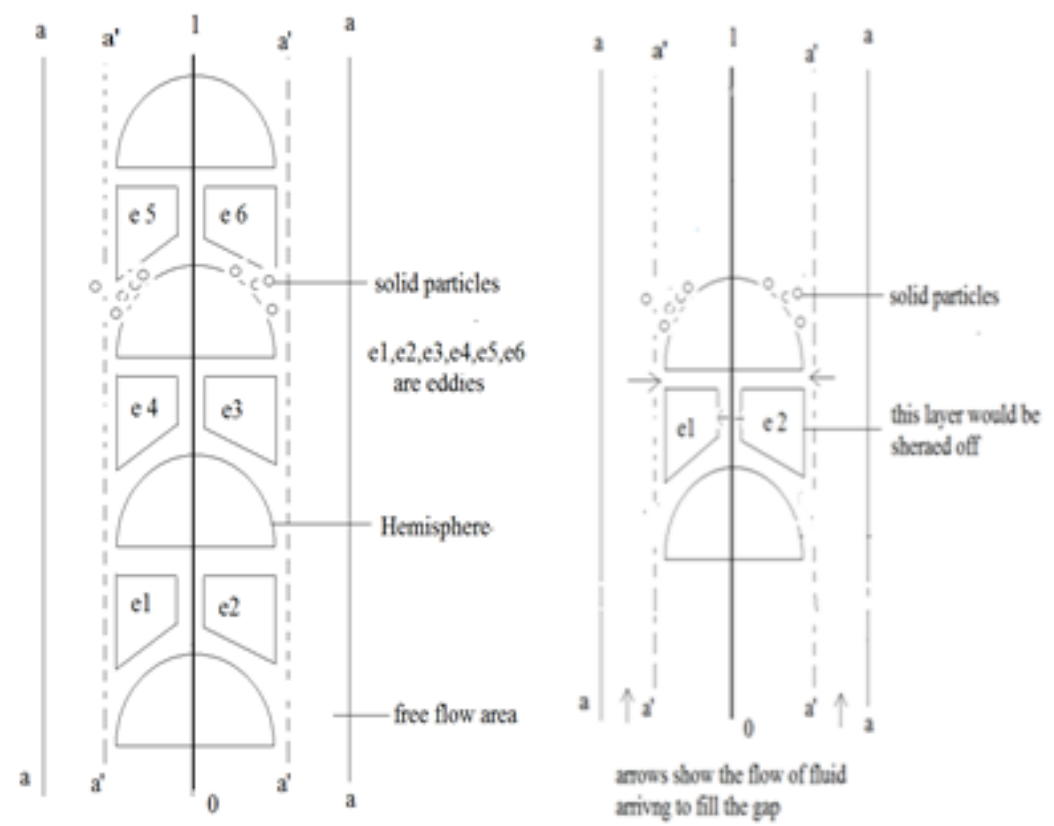

Figure 4a. Flow pattern in the test section

Figure 4b. Movement of eddies

This way churning action is initiated and spreads throughout the free flow zone formed by 'aa', This churning action leads to increased turbulence at wall of the column i.e, represented by surface 'aa' appears to be uniform throughout as is evident from the measured limiting current values at the point electrodes.

Since local mass transfer coefficients vary in the longitudinal direction, all electrodes were shorted and a mean mass transfer coefficient value $\mathrm{k}_{\mathrm{L} \text {,avg }}$ is computed and used in proceeding discussion.

\subsection{Effect of gas and liquid velocities on $\mathbf{k}_{\mathbf{l}, \text { avg }}$}

The mass transfer coefficient data in a gas-liquid fluidized bed in the presence of string of hemispheres $\left\{\mathrm{p}=5.0 \mathrm{~cm}, \mathrm{~d}_{\mathrm{r}}=\right.$ $\left.0.6 \mathrm{~cm}, \mathrm{~d}_{\mathrm{b}}=4.0 \mathrm{~cm}, \mathrm{~d}_{\mathrm{P}}=4.243 \mathrm{~mm}\right\}$ for three superficial liquid velocities $0.094,0.122$ and $0.15 \mathrm{~m} / \mathrm{s}$ were plotted against superficial gas velocity and shown in Figure 5a. A close inspection of the plots of this figure revealed that the mass transfer coefficient appears to be insignificant with liquid velocity. The reason for this may be that the liquid generates turbulence which is not that significant compared to the total turbulence generated in the bed. 


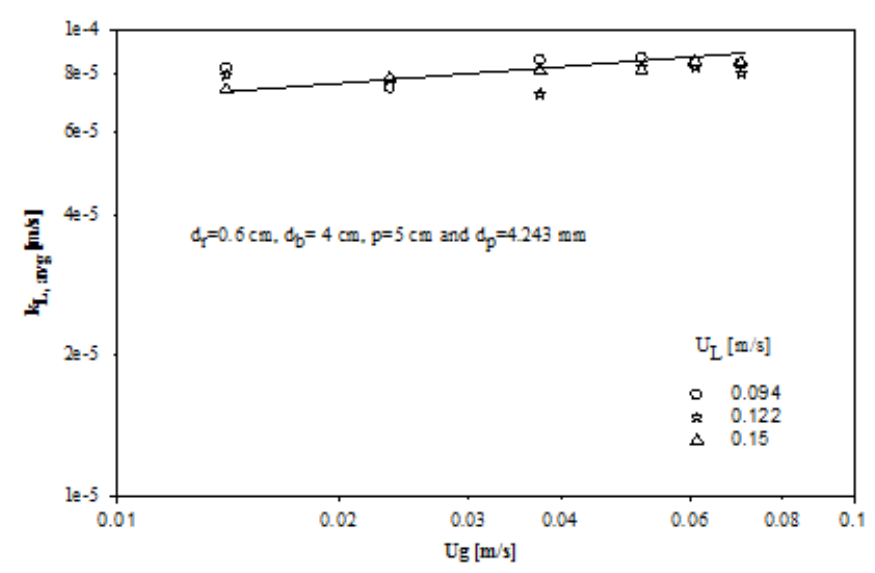

Figure 5a. Variation of $\mathrm{k}_{\mathrm{L}, \text { avg }}$ with superficial gas velocity $\mathrm{U}_{\mathrm{g}}$

The mass transfer coefficient data obtained in a three-phase fluidized bed in the presence of string of hemispheres promoter $\left\{\mathrm{p}=5.0 \mathrm{~cm}, \mathrm{~d}_{\mathrm{r}}=0.6 \mathrm{~cm}, \mathrm{~d}_{\mathrm{b}}=4.0 \mathrm{~cm}, \mathrm{~d}_{\mathrm{P}}=4.243 \mathrm{~mm}\right\}$ were plotted for three different superficial gas velocities 0.014 , 0.0234 and $0.0375 \mathrm{~m} / \mathrm{s}$ against superficial liquid velocity and is shown in Figure 5b. The mass transfer coefficient was found to be increasing with an increase in gas velocity and the liquid velocity had exhibited only marginal influence on mass transfer coefficient.

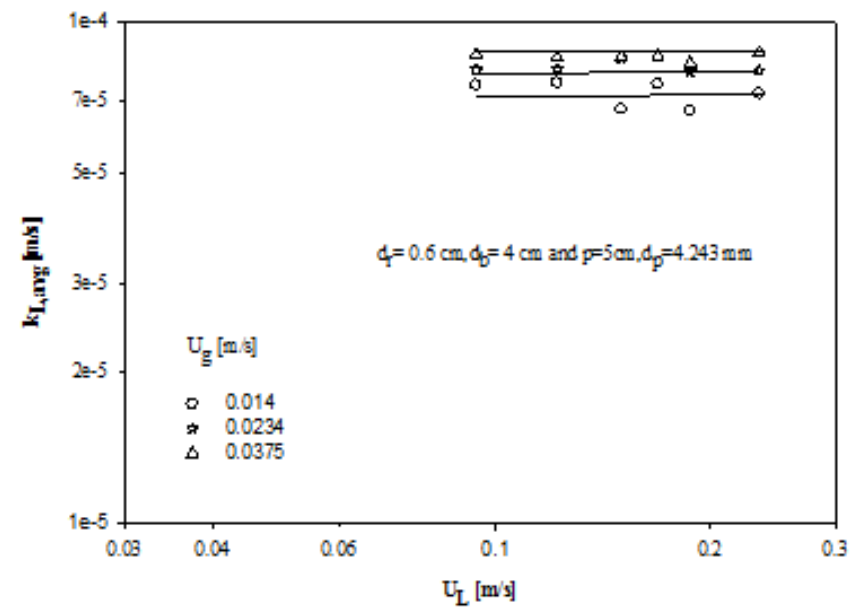

Figure 5b. Variation of $\mathrm{k}_{\mathrm{L}, \text { avg }}$ with superficial liquid velocity $\mathrm{U}_{\mathrm{L}}$

\subsection{Effect of pitch on $k_{L, a v g}$}

The graph plotted between the mass transfer coefficient and gas velocity is shown in Figure 6 for the case of hemispherical promoter. Three different pitches viz., 3,5 and $7 \mathrm{~cm}$ at a constant $d_{r}=1 \mathrm{~cm}, d_{b}=4 \mathrm{~cm}$ and $d_{p}=4.243 \mathrm{~mm}$ for a constant liquid velocity $\mathrm{U}_{\mathrm{L}}=0.1218 \mathrm{~m} / \mathrm{s}$ have been considered. The plots reveal that the mass transfer coefficient values decreased with increase in pitch, which is also evident from the inset of the Figure 6. The reason for this may be attributed as follows. As the fluid flows past the string of hemispheres, the fluid is subjected to a series of sudden contractions and expansions leading to severe churning action. As the pitch is increased, the number of contractions and expansions decreases. Therefore the intensity of churning action decreases. Hence a decreased trend is noticed.

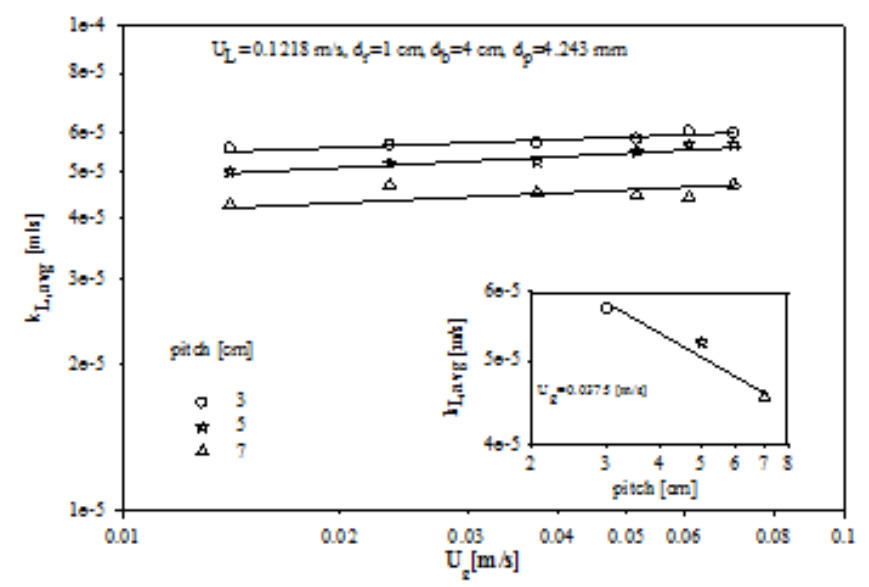

Figure 6. Variation of $\mathrm{k}_{\mathrm{L}, \text { avg }}$ with pitch

\subsection{Effect of characteristic length on $k_{L}$,avg}

Data on $\mathrm{k}_{\mathrm{L}, \mathrm{avg}}$ in the presence of promoter internal $\left\{\mathrm{d}_{\mathrm{r}}=1 \mathrm{~cm}\right.$; $\mathrm{p}=5.0 \mathrm{~cm}\}$ and for a particle size of $4.243 \mathrm{~mm}$ at a constant liquid velocity of $0.1218 \mathrm{~m} / \mathrm{s}$ were plotted against gas velocity for three different characteristic lengths and shown in Figure 7. A close inspection of plots of Figure 7 reveals that the mass transfer coefficient decreased with characteristic length, which is also evident from the inset of the Figure 7.

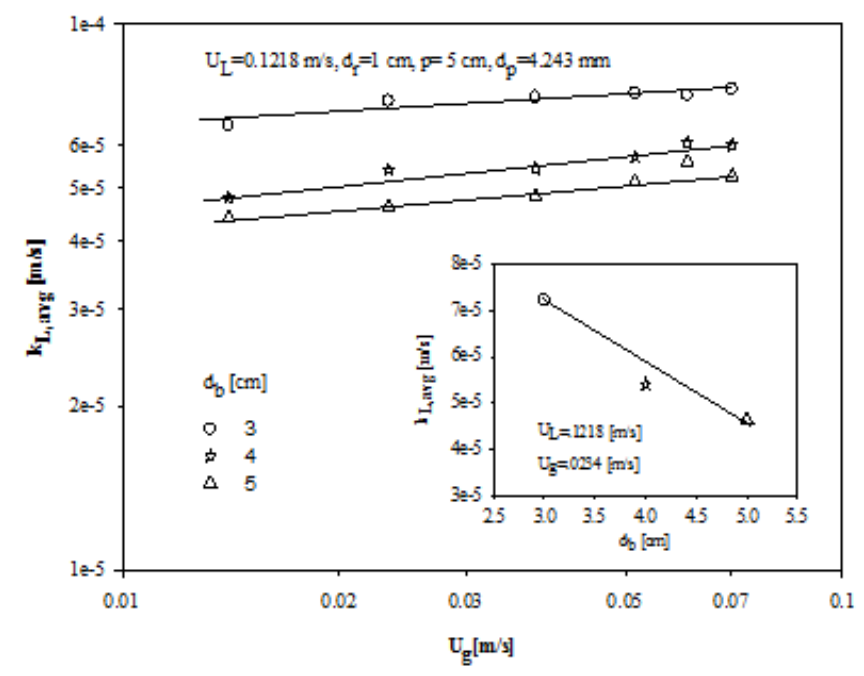

Figure 7. Variation of $\mathrm{k}_{\mathrm{L}, \mathrm{avg}}$ with characteristic length

The increase in characteristic length leads to reduced available flow area, due to which fluid velocities increase proportionally. Because of high velocities the bed becomes lean and results in reduced turbulence. This causes a fall in mass transfer coefficients.

\subsection{Effect of particle diameter on $\mathrm{k}_{\mathrm{L}, \mathrm{avg}}$}

The wall-to-bed mass transfer coefficient data obtained in three-phase fluidized bed with the turbulent promoter internal $\left\{\mathrm{d}_{\mathrm{r}}=1 \mathrm{~cm} ; \mathrm{p}=5.0 \mathrm{~cm} ; \mathrm{d}_{\mathrm{b}}=4 \mathrm{~cm}\right\}$ were plotted against liquid velocity for a constant gas velocity $(\mathrm{Ug}=0.0234 \mathrm{~m} / \mathrm{s})$ for particles of three different sizes (viz., 2.9, 4.243 and $5.6 \mathrm{~mm}$ ) and shown in Figure 8. An increase in particle diameter resulted in a significant increase in mass transfer coefficient 
which is also seen from the inset of Figure 8. The reason for this is attributed as follows. Most of the resistance to mass transfer lies within the fluid film near the wall. The factor adding to reduction in film thickness is the solids circulation causing vigorous turmoil both in the bulk of the electrolyte and at the wall. As the particle diameter increases, its impetus would energize the particle to strike the column wall resulting in thinning of the resistance film. Hence, increased mass transfer coefficients were realized.

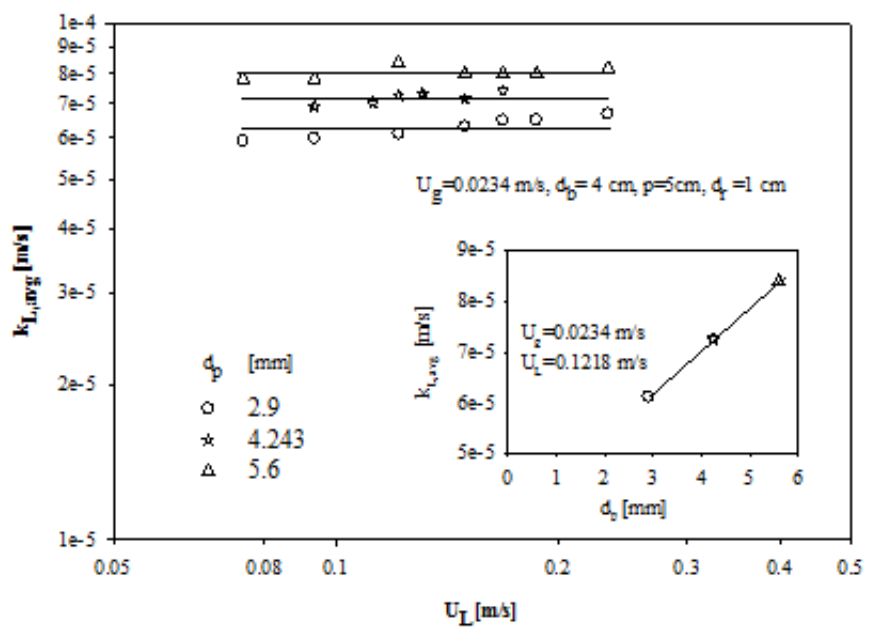

Figure 8. Variation of $\mathrm{k}_{\mathrm{L}, \text { avg }}$ with particle size

\subsection{Effect of rod diameter on $k_{L, a v g}$}

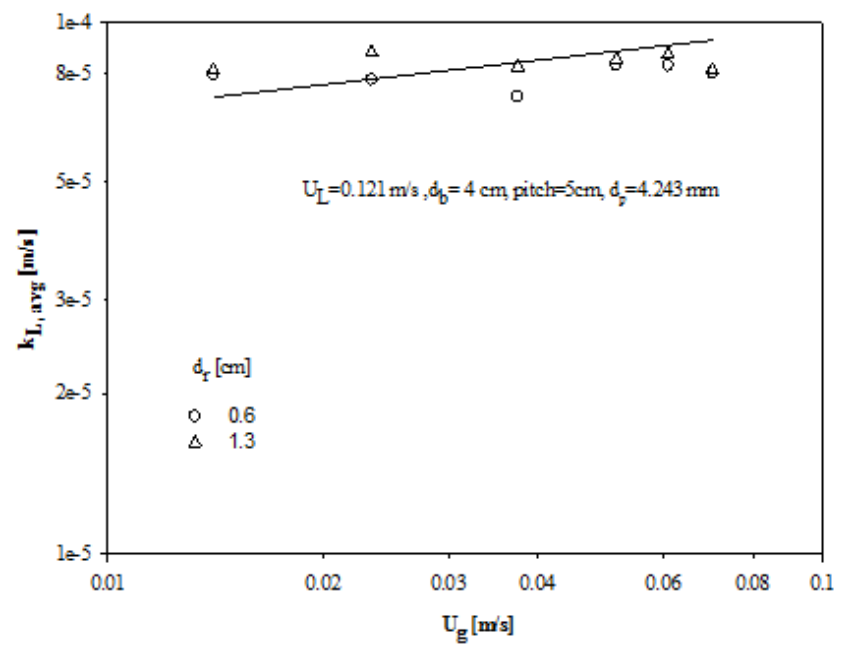

Figure 9. Variation of $\mathrm{k}_{\mathrm{L}, \mathrm{avg}}$ with rod diameter

Figure 9 shows the plots of the data on mass transfer coefficient drawn against superficial gas velocity for two different rod diameters viz., 0.6 and $1.3 \mathrm{~cm}$, for constant $\mathrm{U}_{\mathrm{L}}=0.121 \mathrm{~m} / \mathrm{s}, \mathrm{d}_{\mathrm{b}}=4 \mathrm{~cm}, \mathrm{p}=5 \mathrm{~cm}, \mathrm{~d}_{\mathrm{p}}=4.243 \mathrm{~mm}$. The plots of Figure 9 revealed that the mass transfer coefficient is insignificant with increase in the rod diameter of promoter when liquid velocity was maintained constant at $0.121 \mathrm{~m} / \mathrm{s}$.

\subsection{Correlation}

The entire data on mass transfer coefficient obtained in the present investigation is correlated by least square regression analysis and the following equation is obtained.
$j_{\mathrm{D}} \varepsilon_{\mathrm{L}}=0.39\left[\frac{\mathrm{Re}_{\mathrm{p}} \varepsilon}{\varepsilon_{\mathrm{L}}(1-\varepsilon)}\right]^{-0.23}(\mathrm{Fr})^{0.06}\left(\frac{\mathrm{p}}{\mathrm{d}_{\mathrm{c}}}\right)^{-0.16}\left(\frac{\mathrm{d}_{\mathrm{b}}}{\mathrm{d}_{\mathrm{c}}}\right)^{-0.19}\left(\frac{\mathrm{d}_{\mathrm{r}}}{\mathrm{d}_{\mathrm{c}}}\right)^{0.01}$

The exponent on promoter rod diameter is very small indicating that effect of rod diameter was insignificant and the exponents on pitch and characteristic length are nearly same. Hence both were clubbed and the following new correlation was developed.

$\mathrm{j}_{\mathrm{D}} \varepsilon_{\mathrm{L}=}=0.33\left[\frac{\mathrm{Re}_{\mathrm{p}} \varepsilon}{\varepsilon_{\mathrm{L}}(1-\varepsilon)}\right]^{-0.215}(\mathrm{Fr})^{0.05}\left[\left(\frac{\mathrm{p}}{\mathrm{d}_{\mathrm{c}}}\right)\left(\frac{\mathrm{d}_{\mathrm{b}}}{\mathrm{d}_{\mathrm{c}}}\right)\right]^{-0.18}$

with average deviation of $8.92 \%$ and standard deviation of $11.07 \%$.

The correlation plot for reduction of ferricyanide ion, has been shown in Figure 10. On y-axis $\mathrm{Y}^{\prime \prime}$ has been taken as $\mathrm{j}_{\mathrm{D}} \varepsilon_{\mathrm{L}}(\mathrm{Fr})^{-0.05}\left[\left(\frac{\mathrm{p}}{\mathrm{d}_{\mathrm{c}}}\right)\left(\frac{\mathrm{d}_{\mathrm{b}}}{\mathrm{d}_{\mathrm{c}}}\right)\right]^{0.18}$ and on $\mathrm{X}$-axis $\left[\frac{\mathrm{Re}_{\mathrm{p}} \varepsilon}{\varepsilon_{\mathrm{L}}(1-\varepsilon)}\right]$ has been taken.

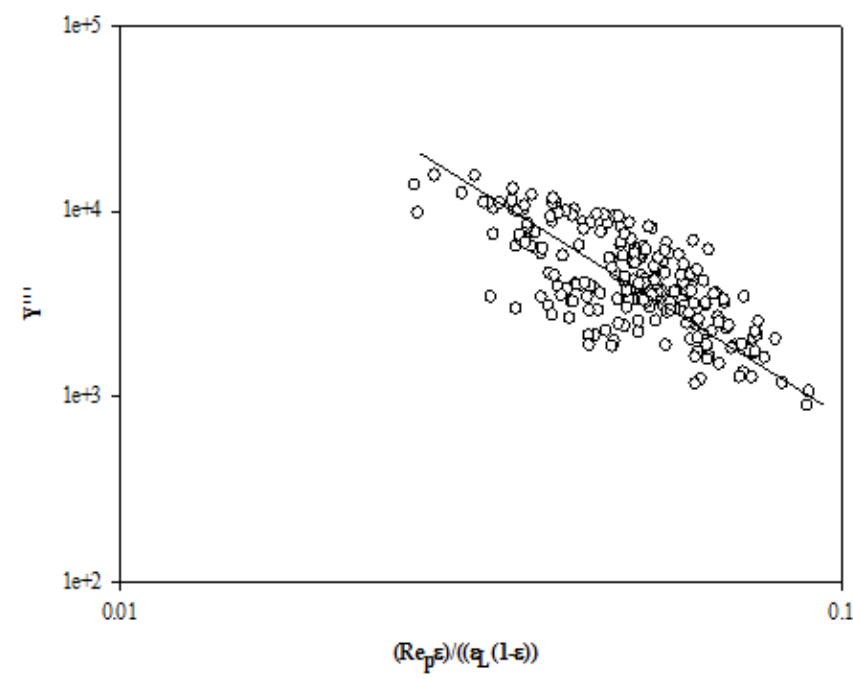

Figure 10. Correlation plot according to equation (4)

\section{CONCLUSIONS}

The presence of string of hemispheres as internal in a threephase fluidized bed augmented mass transfer coefficient values nearly by 18 times when compared to homogeneous flow. The mass transfer coefficient was found to increase with increase in gas velocity, but the effect of liquid velocity was insignificant. The mass transfer coefficient got increased with particle size and decreased with pitch and characteristic length. The entire mass transfer data were correlated in $\mathrm{j}_{\mathrm{d}}-\mathrm{Re}$ format of correlation equation.

\section{REFERENCES}

[1] Handbook of heat transfer (1998). New York, McGraw Hill 11.1-11.76.

[2] Sivakumar K, Rajan K. (2015). Experimental analysis of heat transfer enhancement in a circular tube with different twist ratio of twisted tape inserts. International Journal of Heat and Technology 33: 158-162. https://doi.org/ 10.18280/ijht.330324 
[3] Kaliakatsos D, Cucumo M, Ferraro V, Mele M, Galloro A, Accorinti F. (2016). CFD analysis of a pipe equipped with twisted tape. International Journal of Heat and Technology 34(2): 172-180. https://doi.org/ 10.18280/ijht.340203

[4] Ramesh KV, Raju GMJ, Murty MSN, Bhaskara Sarma C. (2009). Wall to bed mass transfer in three phase fluidized beds in the absence and presence of a composite promoter. Chemical Engineering Journal 152: 207-211. https://doi.org/10.1016/j.cej.2009.04.048

[5] Murty MSN, Ramesh KV, Venkateswarlu P, Prabhakar G. (2010). Ionic mass transfer in three-phase fluidized beds in the presence of disc promoters. Chemical Engineering Communications 198: 1018 https://doi.org/10.1080/00986445.2011.545302

[6] Subramanyam BS, Murty MSN, Babu BS, Ramesh KV. (2014). Wall-to-bed mass transfer in a three-phase fluidized bed with twisted tape as internal, Journal of The Institution of Engineers (India): Series E 95(1): 4956. https://doi.org/10.1007/s40034-014-0035-z

[7] Rohini Kumar P, Ashok Kumar K, Murty MSN, Ramesh KV. (2017). Wall-to-bed mass transfer in three-phase fluidized beds in the presence of angled disc promoter. Heat and Mass Transfer 53(10): 3129-3140. https://doi.org/10.1007/s00231-017-2056-x

[8] Rohini Kumar P, Niranjana Rao B, Venkateswarlu P, Ramesh KV. (2018). Wall-to-bed mass transfer in a three-phase fluidized bed with coaxially placed string of spheres internal. Materials Today Proceedings 5: 470476. https://doi.org/10.1016/j.matpr.2017.11.107

[9] Reddy GVSK, Murthy MSN, Srinivas B, Ramesh KV. (2014). Liquid-wall mass transfer in homogeneous flow with coaxially placed string of hemispheres. Journal of The Institution of Engineers (India): Series E 95(2): 69-74. https://doi.org/10.1007/s40034-014-00402

[10] Reddy GVSK. (2016). Wall-to-bed mass transfer in fluidized beds with coaxially placed string of hemispheres. Ph.D. thesis. Dept. of Chemical Engineering, Andhra University, Visakhapatnam, India.

[11] Lin CS, Denton EB, Gaskill HS, Putan CL. (1951). Diffusion controlled electrode reactions. Ind. Eng. Chem. 43: 2136-2143. https://doi.org/ 10.1021/ie50501a045

[12] Harvind Kumar R, Ramesh KV, Sarma GVS, Raju. GJM. (2011). Mass transfer at the confining wall of helically coiled circular tubes in the absence and presence of packed solids. International Communications in Heat and
Mass $\quad$ Transfer $\quad 38:$ 319-323. https://doi.org/10.1016/j.icheatmasstransfer.2010.11.00 8

[13] Jagannadha Raju GJV, Venkata Rao C (1965). Ionic mass transfer in the presence of fluidized solids, Indian Journal of Technology 3(7): 201-205.

[14] Yasunishi A, Fukuma M, Muroyama K. (1988). Wall-toliquid mass transfer in packed and fluidized beds with gas-liquid counter flow. Journal of Chemical Engineering. of Japan 21: 522-528. https://doi.org/10.1252/jcej.21.522

[15] Venkateswarlu P, Gopichand T, JaganadhaRaju GJV. (2000). Increased mass transfer in a circular column in the presence of disc promoter. Journal of Energy, Heat and Mass Transfer 22: 195-203.

[16] Sarma GVS, Murty MSN, Ramesh KV, Raju GJM. (2011). Wall to bulk mass transfer in gas liquid up flow bubble column with disc promoter. Journal of energy, Heat and Mass Transfer 33: 233-249.

\section{NOMENCLATURE}

A Area of the reacting surface $\left[\mathrm{m}^{2}\right]$

$\mathrm{C}_{0} \quad$ Concentration of ferricyanide ion $\left[\mathrm{kmol} / \mathrm{m}^{3}\right]$

$\mathrm{d}_{\mathrm{c}} \quad$ Column diameter [m]

$\mathrm{d}_{\mathrm{b}} \quad$ Characteristic length $=$ diameter of the ball $[\mathrm{m}]$

$\mathrm{d}_{\mathrm{r}} \quad$ Diameter of the rod $[\mathrm{m}]$

$\mathrm{d}_{\mathrm{p}} \quad$ Diamter of the solid particles [m]

$\mathrm{D}_{\mathrm{L}} \quad$ Diffusivity of reacting ion $\left[\mathrm{m}^{2} / \mathrm{s}\right]$

F Faraday constant [C/mol of electrons]

$\mathrm{i}_{\mathrm{L}} \quad$ Limiting current $[\mathrm{A}]$

$\mathrm{k}_{\mathrm{L}} \quad$ Mass transfer coefficient $[\mathrm{m} / \mathrm{s}]$

$\mathrm{k}_{\mathrm{L}}$,avg Average mass transfer coefficient $[\mathrm{m} / \mathrm{s}]$

$\mathrm{p} \quad$ Pitch $[\mathrm{m}]$

$\mathrm{U}_{\mathrm{L}} \quad$ Superficial Liquid Velocity $[\mathrm{m} / \mathrm{s}]$

$\mathrm{U}_{\mathrm{g}} \quad$ Superficial gas Velocity [m/s]

$\mathrm{n} \quad$ Number of electrons released or consumed during the reaction

$\mu \quad$ Viscocity of electrolyte [Pa.s]

$\rho \quad$ Density of the electrolyte $\left[\mathrm{kg} / \mathrm{m}^{3}\right]$

$\varepsilon \quad$ Bed porosity

$\varepsilon_{\mathrm{L}} \quad$ Liquid holdup

$j_{D} \quad$ Mass transfer factor $=\frac{k_{L}}{U_{L}} S c^{2 / 3}$

$\mathrm{Re}_{\mathrm{p}} \quad$ Particle Reynolds number $=\frac{\rho d_{p} U_{L}}{\mu}$

Sc $\quad$ Schmidt number $=\frac{\mu}{\rho D_{L}}$ 